\title{
ENGEVISTA
}

Página da revista: http://www.uff.br/engevista/seer/

\section{Avaliação da viabilidade celular de levedura cultivada em permeado de soro de queijo após secagem}

\author{
Grettya Maria Assunção ${ }^{1}$ \\ Matheus da Silva Lucas ${ }^{2}$ \\ Mônica Lady Fiorese ${ }^{3}$ \\ Edson Antonio da Silva ${ }^{4}$ \\ Izabela Miotto 5 \\ Barbara Lepretti de Nadai ${ }^{6}$ \\ Camila Larissa Hinterholz ${ }^{7}$
}

\begin{abstract}
Resumo: A produção de Concentrado Proteico de Soro (CPS) gera como subproduto o permeado de soro de queijo que é rico em água, sais minerais e lactose, e é passível de ser utilizado como fonte de carbono em processos biotecnológicos. Um emprego do permeado é no cultivo de Sacharomyces boulardi, levedura probiótica, gerando um produto com biomassa, meio de cultivo e elevado teor de umidade que, para algumas aplicações na indústria, necessita ser removida. A secagem é uma alternativa para o processamento da biomassa desde que realizada de forma efetiva e em condições brandas de temperatura para evitar a perda da viabilidade celular. O objetivo deste trabalho foi avaliar a viabilidade celular de $S$. boulardi, pós-secagem em estufa de circulação forçada, desidratador e spray dryer, analisar a composição físico-química da biomassa in natura e após secagem, além da cinética de secagem para os secadores descontínuos investigados. Para tal, foram feitas secagens com amostras de biomassa mais o meio de cultivo (amostra A) e amostras de biomassa previamente centrifugada, removendo o sobrenadante (amostra B). Foram testados diferentes modelos matemáticos para descrever a cinética de secagem dos procedimentos descontínuos e o modelo de Page foi o que melhor
\end{abstract}

\footnotetext{
${ }^{1}$ Unioeste - Universidade Estadual do Oeste do Paraná

${ }^{2}$ Unioeste - Universidade Estadual do Oeste do Paraná

${ }^{3}$ Unioeste - Universidade Estadual do Oeste do Paraná

${ }^{4}$ Unioeste - Universidade Estadual do Oeste do Paraná

${ }^{5}$ Unioeste - Universidade Estadual do Oeste do Paraná

${ }^{6}$ Unioeste - Universidade Estadual do Oeste do Paraná

${ }^{7}$ Unioeste - Universidade Estadual do Oeste do Paraná
} 
ISSN: $1415-7314$

ISSN online: 2317-6717

representou o comportamento dos dados experimentais. Para todas as condições testadas, não houve perdas significativas em relação à viabilidade celular da levedura, sendo após os procedimentos de secagem mantidos acima de $90 \%$ de células viáveis.

Palavras-chave: Saccharomyces boulardii, probiótico, desidratação.

\begin{abstract}
The production of Whey Protein Concentrate (WPC) generates as a by-product the cheese whey permeate, which is rich in water, lactose and minerals, and is likely to be used at a reuse level, as carbon source in biotechnological processes. A usage of the permeate is in the growth of Saccharomyces boulardi, a probiotic yeast, generating a product with biomass, growth medium and high moisture content which, for some applications in the industry, needs to be removed. The drying is an alternative for the biomass processing, if carried out effectively and in mild temperature conditions to prevent loss of cell viability. The aim of this study was to evaluate the cell viability after drying in an oven with forced air circulation, dehydrator and spray dryer, to analyze the physicochemical biomass composition without any treatment and after drying, besides the drying kinetics for the batch dryers investigated. Therefore, drying using biomass samples plus the growth medium (sample A) and biomass samples previously centrifuged, removing the supernatant (sample B) were made. Different mathematical models were tested to describe the drying kinetics of the discontinuous procedures and the Page model was the one that best represented the behavior of the experimental data. For all the tested conditions, there were no significant losses when it comes to the yeast cell viability, and after drying procedures over $90 \%$ of viable cells were maintained.
\end{abstract}

Keywords: Saccharomyces boulardii, drying, cell viability. 
ISSN: $1415-7314$

ISSN online: $2317-6717$

\section{Introdução}

O processo de produção do queijo gera o soro de leite que possui cerca de 90 a $95 \%$ do volume inicial do leite, e que, se tratado como resíduo e descartado ao meio ambiente se torna um potencial poluidor uma vez que sua composição possui 55\% dos nutrientes presentes originalmente no leite, sendo grande parte deles açúcares e proteínas (Kosikowski, 1979; Zall, 1984; Morr, 1985; Ghaly \& Ben, 1997; Siso, 1996; Araújo et al., 2009; Prazeres et al., 2012).

Uma alternativa explorada atualmente para o reaproveitamento do soro é a produção de Concentrados Proteicos de Soro (CPS), usualmente conhecido como Whey Protein, base para suplementos alimentares com elevados valores nutricionais. Neste processo ocorre a geração de um novo subproduto denominado permeado de soro de leite, o qual é constituído basicamente por água, sais minerais e elevado teor de lactose (80-90\%). Este subproduto pode ser utilizado como fonte de carbono na obtenção de outros produtos em processos biotecnológicos com altos níveis de nutrientes e elevado valor agregado (Araújo et al., 2009).

Um exemplo dessa utilização é o cultivo da levedura Saccharomyces boulardii, uma levedura não patogênica de origem ambiental, termotolerante utilizada como probiótico funcional, que se consumida periodicamente traz, principalmente, benefícios para o ser humano no balanço da flora microbiana dos indivíduos (Krueger et al., 2008).

Estudos revelaram ainda sua grande ação no organismo humano, combatendo vários tipos de distúrbios gastrointestinais como a diarreia associada ao uso de antibióticos e o tratamento da diarreia causada pelo Clostridiun difficile (Surawicz, 2003).

Para a produção da levedura é necessário, muitas vezes, que se apliquem procedimentos de secagem que não destruam as células.

Segundo Oi et al. (2012), a secagem aumenta a vida de prateleira dos produtos, além de facilitar etapas de manuseio, armazenamento e transporte dos produtos, sendo uma importante e fundamental etapa no processo de produção e comercialização da levedura. Para isso, as condições de secagem não devem ser demasiadamente agressivas para que a levedura se mantenha viável após os procedimentos de secagem (Joshi e Thorat, 2011).

A análise da viabilidade celular é de extrema importância para determinar a eficiência da secagem e um ponto crucial na escolha do tipo de secagem a ser utilizada.

No grupo de secadores contínuos se encontra o secador por nebulização chamado spray dryer, que remove a umidade de produtos em apenas uma etapa. Essa operação reúne padrões elevados de qualidade com relação à forma, densidade, homogeneidade, umidade final e granulometria, aspectos que podem ser alterados modificando os parâmetros do procedimento (Remili et al., 1994). Além disso, a secagem realizada em spray dryer é capaz de processar uma grande variedade de matérias primas, em condições assépticas (Etzel, 1996). Os secadores descontínuos, por sua vez, são aqueles indicados para produções em pequena escalas, como as estufas de circulação forçada e desidratadores. 
ISSN: $1415-7314$

ISSN online: $2317-6717$

O projeto de secadores em batelada requer a avaliação da cinética para cada tipo de material biológico, pois cada um possui características próprias e propriedades que podem sofrer importantes alterações durante a secagem (Park et al., 2001).

O desenvolvimento de modelos matemáticos auxilia no projeto desses secadores e, com isso, é possível aperfeiçoar o processo prevendo seu comportamento (Afazl \& Abe, 2000). E o uso de modelagens com auxílio de equações empíricas pode descrever a cinética de diversos produtos (Madamba, 2003)

O objetivo deste trabalho foi testar diferentes procedimentos de secagem de $S$. boulardii com intuito de avaliar o desempenho frente à viabilidade celular, e assim modelar curvas de secagem que podem auxiliar na otimização de tais procedimentos em batelada. Para isso, foi utilizado como matéria-prima no cultivo de $S$. boulardii o subproduto do processo de fabricação do Whey Protein denominado permeado de soro de leite.

\section{Material e métodos}

\subsection{Produção de Biomassa}

O micro-organismo cultivado foi a Saccharomyces boulardii obtido na forma liofilizada a partir do medicamento Floratil, da marca Merck ${ }^{\mathrm{TM}}$. Cada cápsula de $200 \mathrm{mg}$ de $S$. boulardii continha cerca de $1 \times 10^{9}$ células.

As condições de cultivo utilizadas para obtenção da biomassa microbiana foram baseadas nos estudos de Souza et al. (2011), sendo o substrato principal o resíduo permeado de soro de leite cedido pela empresa SOORO Concentrado Indústria de Produtos Lácteos Ltda., localizada na cidade de Marechal Candido Rondon, região oeste do Paraná. O tempo de cada cultivo foi de $30 \mathrm{~h}$.

O meio de cultivo, após fermentado, foi dividido em duas amostras (A e B). A amostra A era constituída pelo meio mais a biomassa, e a amostra B passou por um processo de centrifugação (em centrífuga da marca Parsec modelo CT-0603 a 3000 rpm por 5 min), para separar o sobrenadante (meio de cultivo) do precipitado (biomassa). Ambas as amostras foram armazenadas em refrigerador até a utilização nos ensaios de secagem.

\subsection{Determinação do Teor de Umidade Inicial}

Fez-se a determinação da umidade das amostras $\mathrm{A}$ e $\mathrm{B}$ em estufa à temperatura de $105^{\circ} \mathrm{C}$ de acordo com a metodologia proposta pelo Instituto Adolfo Lutz (IAL, 2008). Com os valores de massa inicial e massa final foi calculada a porcentagem de umidade presente em cada amostra, utilizandose a equação 1 .

$$
X=\frac{m_{i}-m_{s}}{m_{s}}
$$


Em que $X$ representa a porcentagem de umidade presente na amostra, $m_{i}$ a massa inicial total da amostra e $m_{s}$ a massa do sólido depois da secagem em estufa.

\subsection{Secagem}

O primeiro procedimento de secagem foi realizado no secador descontínuo representado por uma estufa de circulação forçada (ECF) da marca Solab de modelo SL 102. Nesta etapa experimental as amostras foram secas a 40,55 e $70^{\circ} \mathrm{C}$, seguindo as orientações dos estudos de Joshi e Thorat (2011). Durante a secagem, as amostras foram pesadas periodicamente, até que o produto atingisse a umidade de equilíbrio.

O segundo procedimento de secagem foi realizado no secador, também descontínuo, denominado Desidratador (D), da marca Polidryer, modelo PD-15. Por se tratar de um equipamento similar a estufa de circulação forçada, optou-se por utilizar somente a temperatura de $55^{\circ} \mathrm{C}$ para fins de comparação, em que também se pesou periodicamente as amostras e determinou-se a vazão de ar de entrada do equipamento com o auxílio do anemômetro.

No terceiro procedimento de secagem foi utilizado um spray dryer (SD) da marca Labmaq de modelo MSD 1.0. As condições de operação experimentais foram adaptadas dos estudos de Oliveira et al. (1996), sendo a alimentação $0,55 \mathrm{~L} \mathrm{~h}^{-1}$ de produto aplicado com um bico aspersor de $1 \mathrm{~mm}$ e com vazão de ar de $2400 \mathrm{~L} \mathrm{~h}^{-1}$, a uma temperatura de $100{ }^{\circ} \mathrm{C}$. No spray dryer foi necessária uma pré-diluição da amostra B para assegurar uma quantidade de, no máximo, 20\% de volume de sólidos, respeitando assim as recomendações do fabricante para a operação do equipamento.

\subsection{Cinética de Secagem}

Os dados experimentais obtidos nos secadores descontínuos (tempo versus umidade) foram utilizados para determinar a cinética de secagem. Este procedimento não foi aplicado no spray dryer, pois opera em modo contínuo.

Para representar a cinética de secagem foram testados os modelos matemáticos de Lewis (Bruce, 1985), Page (1949), Henderson \& Pabis (1961), Page Modificado (Overhultset et al., 1973) e o Pseudo Segunda Ordem adaptado dos modelos de adsorção observado nos estudos de McKay e Ho (1999). As equações utilizadas para cada modelo são apresentadas na Tabela 1.

Tabela 1 - Equação dos modelos matemáticos utilizados para cinética de secagem

$$
\text { Modelo Equação }
$$




$$
\begin{aligned}
& \text { Lewis } \quad X=\left(X_{0}-X_{e q}\right) e^{-k m t}+X_{e q} \\
& \text { Page } \quad X=\left(X_{0}-X_{e q}\right) e^{-k m t^{n}} \\
& \text { (1949) }+X_{e q} \\
& \text { \&enderson } \quad X=\left(X_{0}-X_{e q}\right) a e^{-k m t} \\
& \text { (1961) }+X_{e q} \\
& \text { Page } \quad X=\left(X_{0}-X_{e q}\right)\left(e^{-k m t}\right)^{n} \\
& \text { Modificado }+X_{e q} \\
& \text { Pseudo } \quad X \\
& \begin{array}{l}
\text { Segunda } \\
\text { Ordem }
\end{array}=X_{0}-\frac{\left(X_{0}-X_{e q}\right)^{2} k m t}{\left(X_{0}-X_{e q}\right) k m t+1}
\end{aligned}
$$

$\mathrm{X}_{0}$ : porcentagem de umidade inicial; $\mathrm{X}_{\mathrm{eq}}$ : porcentagem de umidade no equilíbrio; Km: constante de secagem; t: tempo; a, n: constantes do modelo.

Para ajustar os parâmetros dos modelos matemáticos seguiu-se o procedimento proposto por Kleinubing et al. (2014) fazendo uso do método de otimização matemática Downhill Simplex (Nelder, 1965), com a equação da função objetivo apresentada a seguir:

$$
F_{O b j}=\sum_{i=1}^{N}\left(Y_{i}^{M O D}-Y_{i}^{E X P}\right)^{2}
$$

Em que $Y^{M O D}$ e $Y^{E X P}$ referem-se à umidade calculada pelo modelo matemático e à umidade experimental respectivamente. $F_{O b j}$ é a função objetivo e $N$ é o número de análises experimentais.

Para avaliar qual dos modelos foi mais eficaz em descrever os dados experimentais, utilizouse como primeiro critério o coeficiente de correlação $\left(R^{2}\right)$ representado pela equação 3 :

$$
R^{2}=1-\frac{\sum_{i=1}^{N}\left(Y_{i}^{M O D}-Y_{i}^{E X P}\right)^{2}}{\sum_{i=1}^{N}\left(Y_{i}^{M O D}-\bar{Y}\right)^{2}}
$$

Em que $\bar{Y}$ é o valor médio de todas as umidades. A equação 3 gera um valor de $\mathrm{R}^{2}$ entre $0 \mathrm{e}$ 1, e o modelo é melhor representado quando esse valor é mais próximo a 1.

O segundo critério de escolha foi o proposto por Akaike (1974), o qual utiliza o valor Akaike Information Criterion (AIC). Segundo o autor este parâmetro permite comparar conjuntos de diferentes modelos e dados, sendo o modelo que apresentar o menor valor de AIC o que melhor descreve os dados experimentais. Esse valor pode ser calculado de acordo com a seguinte equação:

$$
A I C=\mathrm{N} \ln \left(\sum_{i=1}^{N}\left(Y_{i}^{M O D}-Y_{i}^{E X P}\right)^{2}\right)+2 p
$$


Sendo $N$ o número de dados experimentais e $p$ o número dos parâmetros ajustáveis do modelo em questão

\subsection{Caracterização das Amostras}

A caracterização química foi realizada seguindo os procedimentos metodológicos propostos pelo Instituto Adolfo Lutz (IAL, 2008), em que se determinou a porcentagem de lipídios, proteínas e cinzas. Para todos os testes fez-se a caracterização das amostras antes da secagem (in natura) e após os procedimentos de secagem.

\subsection{Viabilidade Celular}

Para determinar a viabilidade celular utilizou-se microscópio óptico da marca Bioval, modelo L-1000B para a contagem das células, com auxílio da câmara de Neubauer, marca Marienfeld, com fundo da câmara do campo central de $0,01 \mathrm{~mm}$ e área de $0,0025 \mathrm{~mm}^{2}$. A metodologia utilizada foi adaptada do procedimento desenvolvido por Lee et al. (1981).

\section{Resultados e discussões}

\subsection{Umidade}

Ao secar as amostras A (biomassa mais o meio de cultivo) e B (biomassa previamente centrifugada, removendo o sobrenadante), obteve-se um teor de umidade inicial de $92,37 \%$ e 75,08\% respectivamente.

Essa diferença de umidade pode ser devido ao processo de preparação da amostra B, o qual passa por uma etapa de centrifugação, eliminando a porção liquida presente na mesma e, portanto, concentrando as células (biomassa).

\subsection{Cinética de Secagem}

Os parâmetros ajustados de todos os modelos cinéticos avaliados nas diferentes condições experimentais de secagem são apresentados na Tabela 2, amostra A e na Tabela 3, amostra B.

Observa-se nas Tabelas 2 e 3 que os resultados médios do coeficiente de determinação $\left(R^{2}\right)$ foram todos próximos a 1 , o que indica que os modelos descreveram bem o comportamento dos dados experimentais da cinética de secagem. Isso pode ser justificado devido a similaridade na formulação dos modelos de Lewis, Page (1949), Henderson \& Pabis (1961) e Page Modificado, tendo apenas como diferença a inserção de uma constante ( $a$ ou $n$ ). O modelo de Pseudo Segunda Ordem que teve sua formulação adaptada de um modelo de adsorção, também apresentou bom ajuste, isto pode ser verificado observando-se a boa relação dos dados obtidos pelo modelo com aos dados experimentais. 
A escolha do melhor modelo de secagem pode variar, pois não existe um modelo universal para representar o comportamento de secagem de todos os tipos de sistemas, bem como as condições operacionais. A escolha do modelo deve ser baseada nos dados experimentais e análises estatísticas como os utilizados neste estudo.

O AIC, como já mencionado, também é um critério que pode ser utilizado na identificação do modelo que fornece o melhor ajuste. De acordo com as Tabelas 2 e 3, o valor do parâmetro AIC teve maior variação quando comparado aos valores do coeficiente de correlação $\left(R^{2}\right)$. Sua variação foi de aproximadamente 6,79 a 106,78, para a amostra A, e de -72,37 a -7,49, para amostra B.

Avaliando os valores da Tabela 2 e 3, o melhor modelo de secagem tanto para a amostra A quanto a amostra B, ou seja, o que obteve em média o menor valor do parâmetro AIC (AIC médio de 11,52 e - 67,33 respectivamente) foi o modelo proposto por Page (1949). E, ainda avaliando estes dois critérios ( $\mathrm{AIC}$ e $\mathrm{R}^{2}$ ), o modelo que menos ajustado à secagem das amostras $\mathrm{A}$ e $\mathrm{B}$ foi o de Pseudo Segunda Ordem.

Nas Figuras 1 e 2 são apresentados os dados experimentais obtidos durante a secagem em ECF nas diferentes temperaturas estudadas $\left(40,55\right.$ e $\left.70{ }^{\circ} \mathrm{C}\right)$, dados experimentais obtidos na secagem em desidratador na temperatura de $55^{\circ} \mathrm{C}$ (operando com uma vazão de entrada de ar de $4,26.10^{-2} \mathrm{~m}^{3}$ $\mathrm{s}^{-1}$ ) e os ajustes obtidos pelo modelo de Page (1949) para a amostra A e B.

Ao comparar os resultados obtidos entre a amostra A (umidade inicial de $12 \mathrm{~g}^{\mathrm{de} \mathrm{H}_{2} 0 \mathrm{~g}^{-}}$ ${ }^{1} \mathrm{em}$ base seca) (Figura 1) com a amostra B (umidade inicial de $3 \mathrm{~g} \mathrm{de}_{2} 0 \mathrm{~g}^{-1} \mathrm{em}$ base seca) (Figura 2), a amostra A apresentou tempo de secagem superior a amostra B. Isto pode ser devido a amostra A possuir em sua composição não somente a biomassa, mas ainda o meio de cultivo (líquido), enquanto a amostra B ser constituída apenas de biomassa celular (concentrado). Os trabalhos de Martinazzo et al. (2007) e Reis et al. (2011) relatam que as secagens ocorrem mais rapidamente em temperaturas elevadas apresentando um valor para a constante $\mathrm{k}_{\mathrm{m}}$ maior, o que é confirmado neste estudo, quando observa-se as Figuras 1 e 2, para as curvas de secagem a $70^{\circ} \mathrm{C}$. 
Tabela 2 - Parâmetros cinéticos dos modelos matemáticos para diferentes tipos de secagem da amostra A.

Lewis

Secagen

Xeq

Km

$\mathbf{R}^{2}$

AIC

ECF a $\mathbf{4 0}^{\circ} \mathbf{C} \quad 5,607.10^{-15} \quad 2,424.10^{-03}$

0,9999

72,92

$\mathbf{E C F}$ a $\mathbf{5 5}^{\circ} \mathbf{C} \quad 1,608.10^{-14} \quad 3,891.10^{-03}$

0,9998

62,27

ECF a 70 $^{\circ} \mathrm{C} \quad 6,638.10^{-13} \quad 7,784.10^{-03}$

0,9997

36,20

$\mathrm{D}$ à $\mathbf{5 5}^{\circ} \mathrm{C}$

$5,236.10^{-09}$

$3,768.10^{-03}$

0,9998

65,10

Page (1949)

$\begin{array}{lccccc}\text { Secagem } & \mathbf{X e q} & \mathbf{K m} & \mathbf{n} & \mathbf{R}^{\mathbf{2}} & \text { AIC } \\ \mathbf{E C F} \text { a } \mathbf{4 0}^{\circ} \mathbf{C} & 9,904.10^{-03} & 2,317.10^{-04} & 1,432 & 0,9999 & 20,54 \\ \text { ECF a } \mathbf{5 5}^{\circ} \mathbf{C} & 2,586.10^{-01} & 3,523.10^{-04} & 1,474 & 0,9999 & 8,57 \\ \text { ECF a } \mathbf{7 0}^{\circ} \mathbf{C} & 2,153.10^{-02} & 4,602.10^{-04} & 1,618 & 0,9999 & 6,79 \\ \text { D a } \mathbf{5 5}^{\circ} \mathbf{C} & 4,036.10^{-02} & 2,103.10^{-04} & 1,564 & 0,9999 & 12,26\end{array}$

Henderson \& Pabis (1961)

\begin{tabular}{|c|c|c|c|c|}
\hline Secagem & Xeq & $\mathbf{K m}$ & $\mathbf{a}$ & $\mathbf{R}^{2}$ \\
\hline ECF a $40^{\circ} \mathrm{C}$ & $7,156.10^{-08}$ & $3,031.10^{-03}$ & 1,059 & 0,9999 \\
\hline ECF a $55^{\circ} \mathrm{C}$ & $6,722 \cdot 10^{-04}$ & $4,499.10^{-03}$ & 1,122 & 0,9999 \\
\hline ECF a $7^{\circ} \mathrm{C}$ & $5,374.10^{-03}$ & $7,556.10^{-03}$ & 1,051 & 0,9997 \\
\hline D a $5^{\circ} \mathrm{C}$ & $5,960.10^{-04}$ & $4,770.10^{-03}$ & 1,054 & 0,9999 \\
\hline
\end{tabular}

Page Modificado

$\begin{array}{lccccc}\text { Secagem } & \mathbf{X e q} & \mathbf{K m} & \mathbf{n} & \mathbf{R}^{\mathbf{2}} & \text { AIC } \\ \mathbf{E C F} \text { a } \mathbf{4 0}^{\circ} \mathbf{C} & 7,660.10^{-06} & 1,584.10^{-02} & 0,170 & 0,9999 & 69,30 \\ \text { ECF a 55 }{ }^{\circ} \mathbf{C} & 6,765.10^{-01} & 4,450.10^{-03} & 1,155 & 0,9998 & 63,74 \\ \text { ECF a } \mathbf{7 0}^{\circ} \mathbf{C} & 4,860.10^{-09} & 4,907.10^{-03} & 1,750 & 0,9997 & 37,78 \\ \text { D a 55 } \mathbf{5 5}^{\circ} \mathbf{C} & 2,570.10^{-04} & 2,658.10^{-03} & 1,718 & 0,9999 & 60,18\end{array}$

Pseudo Segunda Ordem

$\begin{array}{lcccc}\text { Secagem } & \mathbf{X e q} & \mathbf{K m} & \mathbf{R}^{\mathbf{2}} & \mathbf{A I C} \\ \mathbf{E C F} \text { a } \mathbf{4 0} \mathbf{0}^{\circ} \mathbf{C} & 1,295.10^{-06} & 2,401.10^{-04} & 0,9998 & 106,78 \\ \mathbf{E C F} \text { a } \mathbf{5 5}^{\circ} \mathbf{C} & 8,644.10^{-10} & 5,683.10^{-04} & 0,9996 & 87,18 \\ \mathbf{E C F ~ a ~ 7 0}{ }^{\circ} \mathbf{C} & 9,518.10^{-08} & 9,144.10^{-04} & 0,9991 & 54,03 \\ \mathbf{D} \text { a } \mathbf{5 5}^{\circ} \mathbf{C} & 2,475.10^{-05} & 6,454.10^{-04} & 0,9997 & 84,53\end{array}$


Tabela 3 - Parâmetros cinéticos dos modelos matemáticos para diferentes tipos de secagem da amostra B.

Lewis

Secagem

\section{Xeq}

0,2903

ECF a $40^{\circ} \mathrm{C}$

0,3725

ECF a $5^{\circ} \mathrm{C}$

0,2952

ECF a $70^{\circ} \mathrm{C}$

0,3450

$\mathrm{D}$ a $\mathbf{5 5}^{\circ} \mathrm{C}$

Page (1949)

Secagem

ECF a $40^{\circ} \mathrm{C}$

ECF a $5^{\circ} \mathrm{C}$

ECF a $7^{\circ} \mathrm{C}$

Xeq

0,3559

0,3970

0,3229

D a $55^{\circ} \mathrm{C}$

0,4729

Henderson \& Pabis (1961)

Secagem

ECF a $40^{\circ} \mathrm{C}$

\section{Xeq}

Km

ECF a $55^{\circ} \mathrm{C}$

0,2980

0,3747

ECF a $7^{\circ} \mathrm{C}$

$9,97 \cdot 10^{-4}$

$D$ a $55^{\circ} \mathrm{C}$

0,3763

Page Modificado

Secagem

ECF a $40^{\circ} \mathrm{C}$

Xeq

0,2903

0,3725

0,2952

0,3592

D a $55^{\circ} \mathrm{C}$

Pseudo Segunda Ordem

$\begin{array}{lcc}\text { Secagem } & \text { Xeq } & \text { Km } \\ \text { ECF a } \mathbf{4 0}^{\circ} \mathbf{C} & 0,3893 & 6,046.10^{-03} \\ \text { ECF a } 5^{\circ} \mathbf{C} & 0,0342 & 1,930.10^{-02} \\ \text { ECF a } \mathbf{7 0}^{\circ} \mathbf{C} & 0,0258 & 2,567.10^{-02} \\ \text { D a } \mathbf{5 5}^{\circ} \mathbf{C} & 0,3836 & 1,890.10^{-03}\end{array}$

$1,197.10^{-02}$

$2,537.10^{-02}$

$2,396.10^{-02}$

$9,120.10^{-04}$

$4,534.10^{-03}$

$5,603 \cdot 10^{-03}$

$9,665.10^{-03}$

$3,063.10^{-03}$

D a $5^{\circ} \mathrm{C}$

0,3836

$1,890.10^{-03}$

$\begin{array}{cc}\mathbf{R}^{\mathbf{2}} & \text { AIC } \\ 0,9999 & -44,96 \\ 0,9999 & -57,91 \\ 0,9999 & -50,23 \\ 0,9999 & -23,61\end{array}$

\section{$\mathbf{R}^{2}$}

AIC

1,144

0,9999

$-53,75$

1,153

0,9999

$-71,97$

1,246

0,9999

$-72,37$

1,435

0,9999

$-71,25$

AIC

1,016

$-43,83$

1,017

0,775

$-57,20$

0,9999

$-36,35$

1,080

0,9974

$-28,02$

0,9999

\section{$\mathbf{R}^{2}$}

AIC

4,437

0,9999

$-40,96$

7,402

0,9999

$-53,91$

5,230

0,9999

$-46,23$

2,251

0,9999

$-19,54$

$\begin{array}{cc}\mathbf{R}^{\mathbf{2}} & \text { AIC } \\ 0,9999 & -20,64 \\ 0,9999 & -18,77 \\ 0,9998 & -15,12 \\ 0,9999 & -7,49\end{array}$




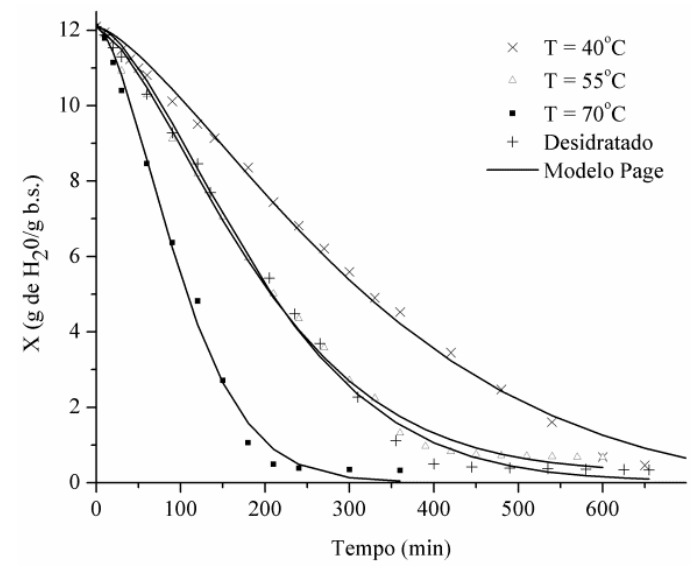

Figura 1 - Dados experimentais e modelo de Page (1949) para a secagem da amostra A

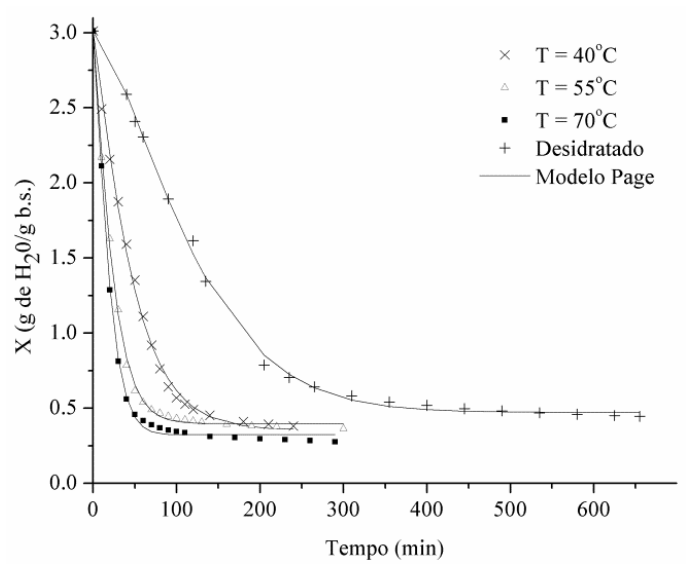

Figura 2 - Dados experimentais e modelo de Page (1949) para a secagem da amostra B

\subsection{Caracterização e Viabilidade Celular}

Ao secar a amostra A em spray dryer obteve-se uma amostra viscosa e úmida, o que provocou um incrustamento nas paredes do equipamento, impossibilitando a coleta da amostra seca. Este problema persistiu mesmo tendo sido realizadas modificações nas condições de operação do equipamento (temperatura, vazão de alimentação da amostra, vazão de alimentação de ar e diâmetro do bico aspersor), sendo possivelmente causado devido a amostra apresentar ainda em sua composição o meio de cultivo, o qual tem como um dos constituintes a fonte de carbono (açúcar), e associado a composição proteica da levedura, que leva a pode levar a ocorrência de reações de Maillard. A Tabela 4 apresenta os valores referentes a caracterização química das amostras (A e B) antes e após secagem, para os diferentes processos testados, com as análises de cinzas, proteína e lipídios. 
Tabela 4 - Caracterização das diferentes amostras antes e após a secagem nos diferentes

\begin{tabular}{lccc}
\multicolumn{3}{c}{ sistemas } & \\
\hline Amostra & Cinzas (\%) & Proteína (\%) & Lipídios (\%) \\
Amostra A & 28,00 & 1,58 & N.D. \\
Amostra A (ECF) & 28,00 & 13,83 & 0,04 \\
Amostra A (D) & 29,65 & 13,62 & 0,25 \\
Amostra A (SD) & N.R. & N.R. & N.R. \\
Amostra B & 15,37 & 15,22 & 0,01 \\
Amostra B (ECF) & 15,37 & 42,15 & 0,16 \\
Amostra B (D) & 16,61 & 45,22 & 0,12 \\
Amostra B (SD) & 10,23 & 42,22 & 0,17 \\
\hline
\end{tabular}

N.D.: Não detectado pelo método utilizado; N.R.: Não realizada.

$\mathrm{Na}$ Tabela 4, verifica-se que os processos de secagem estudados não afetaram a composição físico-química da levedura. Observa-se também que para ambas as amostras (A e B), a biomassa não se degradou, não havendo aumento na concentração de cinzas. Ainda observa-se que a secagem apenas concentrou as amostras, aumentando a porcentagem de proteínas. Esse aumento na concentração é vantajoso, uma vez que a levedura pode também ser utilizada como alternativa a fontes proteicas convencionais, como citado no estudo realizado por Araujo et al. (2009).

É importante também avaliar a resistência das células após a secagem, de forma a se conhecer a viabilidade para posterior uso como probiótico. Realizou-se a análise da viabilidade celular das amostras antes e após submissão aos diferentes procedimentos de secagem, os quais são apresentados na Tabela 5 .

Tabela 5 - Viabilidade Celular das amostras

\begin{tabular}{lc} 
Tipo das amostras & \% Células Vivas \\
Amostra A & 100,00 \\
Amostra A (ECF) & 92,86 \\
Amostra A (D) & 100,00 \\
Amostra B (SD) & N.R. \\
Amostra B & 100,00 \\
Amostra B (ECF) & 99,28 \\
Amostra B (D) & 100,00 \\
Amostra B (SD) & 99,45 \\
\hline
\end{tabular}

N.R.: Não realizado. 
Verifica-se na Tabela 5, que os resultados obtidos para os diferentes procedimentos de secagem, em relação as amostras in natura (viabilidade de 100\%), não apresentaram valores de morte celular elevados, sendo o procedimento de secagem da amostra A em EFC o que apresentou a maior perda de viabilidade celular (perda de viabilidade de $7,14 \%$ ). O procedimento de secagem que manteve a melhor viabilidade celular, permanecendo inalterada (viabilidade de 100\%), foi empregando o desidratador em ambas as amostras, isto pode ser justificado, pelo fato do desidratador utilizado neste trabalho ser classificado como um secador adiabático onde o calor é conduzido por meio de uma corrente de ar quente e o calor é transmitido fundamentalmente por convecção, não entrando assim, a amostra em contato direto com uma superfície aquecida.

Duongthingoc et al. (2014) avaliaram a secagem em spray dryer da S. bourlardii, obtendo também alta viabilidade celular, o valor inicial aproximado de células viáveis foi de $8,1 \log$ UFC.mL $L^{-1}$, e ao final na melhor condição obteve aproximadamente $7,4 \log$ UFC.mL $\mathrm{mL}^{-1}$, o que em termo de porcentagem equivale a uma viabilidade celular após secagem de $91,35 \%$.

De forma geral, mesmo com ação de calor, a levedura manteve alta viabilidade em todos os casos, mostrando a taxa de mortalidade sempre abaixo de um décimo, sendo este um fator importante tendo em vista a sua utilização como alimento probiótico.

\section{Conclusões}

Em relação aos modelos cinéticos testados o que mostrou melhor ajuste aos parâmetros para os secadores em batelada, foi o modelo de Page (1949) tanto para a amostra A quanto para a amostra B.

Os resultados obtidos em relação a viabilidade celular mostram que os diferentes procedimentos de secagem utilizados para secar a biomassa celular proveniente da levedura $S$. boulardii foram eficientes em todas as condições testadas, com exceção da secagem em spray dryer, em que não foi possível realizar o procedimento de secagem sem a centrifugação do meio.

Como a levedura apresentou alta resistência ao calor, ela pode ser submetida aos procedimentos de secagem avaliados neste estudo, como uma das etapas para a sua conservação, pois não houve alteração ou redução expressiva na viabilidade celular, sendo este um fator importante por se tratar de uma levedura probiótica, uma vez que o intuito seja manter as suas propriedades funcionais.

\section{Agradecimentos}

A Fundação Araucária e Conselho Nacional de Desenvolvimento Científico e Tecnológico pelo apoio financeiro no desenvolvimento deste estudo; a Universidade Tecnológica Federal do Paraná - Medianeira pelo empréstimo do equipamento spray dryer e a empresa SOORO Ingredientes, localizada na cidade de Marechal Candido Rondon-PR. 


\section{Referências}

AFZAL, T. M.; ABE, T. 2000. Simulation of moisture changes in barley during far infrared radiation dryin. Computers and Electronics in Agriculture, 26, 137-145.

AKAIKE, H., 1974. A new look at the statistical model identification. IEEE Transactions on Automatic Control, Boston, 19, 716-723.

ARAÚJO, L. de F.; DIAS, M. V. C.; BRITO, E. A. de; OLIVEIRA JUNIOR S. 2009. Enriquecimento proteico de alimentos por levedura em fermentação semissólida: alternativa na alimentação animal. Tecnologia \& Ciencia Agropecuária, 3, 47-53.

BRUCE, D. M. 1985. Exposed-layer barley drying, three models fitted to new data up to $150^{\circ} \mathrm{C}$. Journal of Agricultural Engineering Research, 32, 337-347.

DUONGTHINGOC, D.; GEORGE, P.; GORCZYCA, E.; KASAPIS, S. 2014. Studies on the viability of saccharomyces boulardii within microcapsules in relation to the thermomechanical properties of whey protein. Food Hydrocolloids, 42, 232-238.

ETZEL, M. R. 1996. Enzyme inactivation in a droplet forming a bubble during drying. Journal of Food Engineering, 27, 17-34.

GHALY, A.E.; EL-TAWEEL, A.A. 1997. Kinetic modeling of continuous production of ethanol from cheese whey. Biomass and Bioenergy, 2, 461-72.

HENDERSON, S. M.; PABIS, S. 1961. Grain drying theory. II. Temperature effects on drying coefficients. Journal of Agricultural Engineering Research, 6, 169-174.

IAL - INSTITUTO ADOLFO LUTZ. 2008. Leites e derivados. In: ZENEBOM, O.; PASCUET, N. S.; TIGLEA, P. Métodos físico-químicos para análise de alimentos. 1. ed. digital. São Paulo: Instituto Adolfo Lutz.

JOSHI, V. S.; THORAT, B. N. 2011. Formulation and Cost-Effective Drying of Probiotic Yeast. Drying Technology, 29, 749-757.

KLEINUBING, S. A.; SERAPHIM, D. C.; VIEIRA, M. G. A.; CANEVESI, R. L. S.; SILVA, E. A.; CÉSAR, C. L.; MEI, L. H. I. 2014. Gastro-Resistant Controlled Release of OTC Encapsulated in Alginate/Chitosan Matrix Coated with Acryl-EZEVR MP in Fluidized Bed. Journal of Applied Polymer Science, 131, 40444.

KOSIKOWSKI, F.V. 1979. Whey Utilization and Whey Products. Journal of Dairy Science, v. 62, n. 7, p. 1149-1160.

KRUGER, R. 2008. Desenvolvimento de uma bebida láctea probiótica utilizando como substratos soro de leite e extrato hidrossolúvel de soja. Alimentos e Nutrição, 19, 43-53.

LEE, S. S.; ROBINSON, F. M.; WANG, H. Y. 1981. Rapid determination of yeast viability. Biotechnology and Bioengineering. 11, 641-649.

MADAMBA, P.S. 2003. Thin layer drying models for osmotically pre-dried Young coconut. Drying Technology, 21, 1759-1780.

MARTINAZZO, A. P.; CORRÊA, P. C.; MELO, E. C.; BARBOSA, F. F. 2007. Difusividade efetiva em folhas de Cymbopogon citratus (DC.) submetidas à secagem com diferentes comprimentos de corte e temperaturas do ar. Revista Brasileira de Plantas Medicinais, 9, 68-72.

McKAY G., HO Y.S. 1999. Pseudo-second order model for sorption processes, Process Biochemistry. 34, 451-465.

MORR, C.V. 1990. Effect of heating and elevated temperature storage on cheese whey. Journal of Food Science, v. 55, n. 4, p. 1177-1179.

NELDER, J. A.; MEAD, R. 1965. A Simplex Method for Function Minimization. The Computer Journal, 7, 308-313.

OI, R. K.; TAMBOURGI, E. B.; MORAES JR, D. 2012. Estudo da secagem da biomassa de banana verde em spray dryer. Engevista, 14, 165-171.

OLIVEIRA, C. A.; LIEBSCH, A. E.; GIMENES, M. L. 1996. Características de leveduras secas obtidas em spray dryer. Congresso Brasileiro de Sistemas Particulados, Uberlândia, Brasil. 259264. 
OVERHULTS, D. G.; WHITE, G. M.; HAMILTON, H. E.; ROSS, I. J. 1973. Drying soybeans with heated air. Transactions of American Society of Agricultural Engineers, 16, 112-113.

PAGE, G. E. 1949. Factors influencing the maximum rates of air drying shelled corn in thin layers. M. S. thesis. Purdue University.

PARK, K. J.; YADO, M. K. M.; BROD, F. P. R. 2001. Estudo de secagem de pêra Bartlett (Pyrussp.) em fatias. Ciência e Tecnologia de Alimentos, 21, 288-292.

PEZZATO, A. C. Utilização de levedura na alimentação de monogástricos: Aves. Simpósio sobre aproveichamento de los subproductos de la agroindústria em la alimentácion animal, 1985 Botucatu, Brasil.

PRAZERES, A.R.; CARVALHO, F.; RIVAS, J. 2012. Cheese whey management: A review. Journal of Environmental Management, 110, 48-68.

REIS, R. C.; BARBOSA, L. S.; LIMA, M. L.; REIS, J. S.; DEVILLA, I. A.; ASCHERI, D. P. R. 2011. Modelagem matemática da secagem da pimenta cumari do Pará. Revista Brasileira de Engenharia Agrícola e Ambiental, 15, 347-353.

REMILI, H.; BOUSSOARD, P; DEVLEESCHOUWER, M. 1994. Microbiological quality of spray-dried pharmaceutical plants extracts. European Journal of Pharmaceutical Sciences, 1, 265-268.

SISO, M.I.G. 1996. The biotechnological utilization of cheese whey: A review. Bioresource Technology, 57, 1-11.

SOUZA, R. B. de; COSTA, F. G. P.; LIMA, M. R. de; PINHEIRO, S. G. 2011. Utilização de leveduras de cana-de-açúcar (Saccharomyces cerevisiae) nas rações de aves. Revista Eletrônica Nutritime, 8, 1632-1646.

SURAWICZ, C. M. 2003. Probiotics, antibiotic associated diarreioea and Clostridium difficile diarreia in humans. Best Practice \& Research Clinical Gastroenterology, 17, 775-783.

ZALL, R.R. 1984. Trends in Whey Fractionation and Utilization, a Global Perspective. J Dairy Science, 67, 2621-2629.

AKAIKE, H., 1974. A new look at the statistical model identification. IEEE Transactions on Automatic Control, Boston, 19, 716-723.

ARAÚJO, L. de F.; DIAS, M. V. C.; BRITO, E. A. de; OLIVEIRA JUNIOR S. 2009. Enriquecimento proteico de alimentos por levedura em fermentação semissólida: alternativa na alimentação animal. Tecnologia \& Ciencia Agropecuária, 3, 47-53

BRUCE, D. M. 1985. Exposed-layer barley drying, three models fitted to new data up to $150{ }^{\circ} \mathrm{C}$. Journal of Agricultural Engineering Research, 32, 337-347.

DUONGTHINGOC, D.; GEORGE, P.; GORCZYCA, E.; KASAPIS, S. 2014. Studies on the viability of saccharomyces boulardii within microcapsules in relation to the thermomechanical properties of whey protein. Food Hydrocolloids, 42, 232-238.

ETZEL, M. R. 1996. Enzyme inactivation in a droplet forming a bubble during drying. Journal of Food Engineering, 27, 17-34.

HENDERSON, S. M.; PABIS, S. 1961. Grain drying theory. II. Temperature effects on drying coefficients. Journal of Agricultural Engineering Research, 6, 169-174.

IAL - INSTITUTO ADOLFO LUTZ. 2008. Leites e derivados. In: ZENEBOM, O.; PASCUET, N. S.; TIGLEA, P. Métodos físico-químicos para análise de alimentos. 1. ed. digital. São Paulo: Instituto Adolfo Lutz.

JOSHI, V. S.; THORAT, B. N. 2011. Formulation and Cost-Effective Drying of Probiotic Yeast. Drying Technology, 29, 749-757.

KLEINUBING, S. A.; SERAPHIM, D. C.; VIEIRA, M. G. A.; CANEVESI, R. L. S.; SILVA, E. A.; CÉSAR, C. L.; MEI, L. H. I. 2014. Gastro-Resistant Controlled Release of OTC Encapsulated in Alginate/Chitosan Matrix Coated with Acryl-EZEVR MP in Fluidized Bed. Journal of Applied Polymer Science, 131, 40444.

LEE., S. S.; ROBINSON, F. M.; WANG, H. Y. 1981. Rapid determination of yeast viability. Biotechnology and Bioengineering. 11, 641-649. 
MADAMBA, P.S. 2003. Thin layer drying models for osmotically pre-dried Young coconut. Drying Technology, 21, 1759-1780.

MARTINAZZO, A. P.; CORRÊA, P. C.; MELO, E. C.; BARBOSA, F. F. 2007. Difusividade efetiva em folhas de Cymbopogon citratus (DC.) submetidas à secagem com diferentes comprimentos de corte e temperaturas do ar. Revista Brasileira de Plantas Medicinais, 9, 68-72. McKAY G., HO Y.S. 1999. Pseudo-second order model for sorption processes, Process Biochemistry. 34, 451-465.

NELDER, J. A.; MEAD, R. 1965. A Simplex Method for Function Minimization. The Computer Journal, 7, 308-313.

OI, R. K.; TAMBOURGI, E. B.; MORAES JR, D. 2012. Estudo da secagem da biomassa de banana verde em spray dryer. Engevista, 14, 165-171.

OLIVEIRA, C. A.; LIEBSCH, A. E.; GIMENES, M. L. 1996. Características de leveduras secas obtidas em spray dryer. Congresso Brasileiro de Sistemas Particulados, Uberlândia, Brasil. 259264.

OVERHULTS, D. G.; WHITE, G. M.; HAMILTON, H. E.; ROSS, I. J. 1973. Drying soybeans with heated air. Transactions of American Society of Agricultural Engineers, 16, 112-113.

PAGE, G. E. 1949. Factors influencing the maximum rates of air drying shelled corn in thin layers. M. S. thesis. Purdue University.

PARK, K. J.; YADO, M. K. M.; BROD, F. P. R. 2001. Estudo de secagem de pêra Bartlett (Pyrussp.) em fatias. Ciência e Tecnologia de Alimentos, 21, 288-292.

PEZZATO, A. C. Utilização de levedura na alimentação de monogástricos: Aves. Simpósio sobre aproveichamento de los subproductos de la agroindústria em la alimentácion animal, 1985 Botucatu, Brasil.

REIS, R. C.; BARBOSA, L. S.; LIMA, M. L.; REIS, J. S.; DEVILLA, I. A.; ASCHERI, D. P. R. 2011. Modelagem matemática da secagem da pimenta cumari do Pará. Revista Brasileira de Engenharia Agrícola e Ambiental, 15, 347-353.

REMILI, H.; BOUSSOARD, P; DEVLEESCHOUWER, M. 1994. Microbiological quality of spray-dried pharmaceutical plants extracts. European Journal of Pharmaceutical Sciences, 1, 265-268.

SOUZA, R. B. de; COSTA, F. G. P.; LIMA, M. R. de; PINHEIRO, S. G. 2011. Utilização de leveduras de cana-de-açúcar (Saccharomyces cerevisiae) nas rações de aves. Revista Eletrônica Nutritime, 8, 1632-1646.

SURAWICZ, C. M. 2003. Probiotics, antibiotic associated diarreioea and Clostridium difficile diarreia in humans. Best Practice \& Research Clinical Gastroenterology, 17, 775-783.

KOSIKOWSKI, F.V. 1979. Whey Utilization and Whey Products. Journal of Dairy Science, v. 62, n. 7, p. 1149-1160.

MORR, C.V. 1990. Effect of heating and elevated temperature storage on cheese whey. Journal of Food Science, v. 55, n. 4, p. 1177-1179.

ZALL, R.R. 1984. Trends in Whey Fractionation and Utilization, a Global Perspective. J Dairy Science, 67, 2621-2629.

KRUGER, R. 2008. Desenvolvimento de uma bebida láctea probiótica utilizando como substratos soro de leite e extrato hidrossolúvel de soja. Alimentos e Nutrição, 19, 43-53.

SISO, M.I.G. 1996. The biotechnological utilization of cheese whey: A review. Bioresource Technology, 57, 1-11.

PRAZERES, A.R.; CARVALHO, F.; RIVAS, J. 2012. Cheese whey management: A review. Journal of Environmental Management, 110, 48-68.

GHALY, A.E.; EL-TAWEEL, A.A. 1997. Kinetic modeling of continuous production of ethanol from cheese whey. Biomass and Bioenergy, 2, 461-72.

AFZAL, T. M.; ABE, T. 2000. Simulation of moisture changes in barley during far infrared radiation dryin. Computers and Electronics in Agriculture, 26, 137-145. 